\title{
Formação de conceitos em Geometria e Álgebra por estudante com deficiência visual
}

\author{
Formation of concepts in Geometry and Algebra \\ by a student with visual disability
} Lúcia Virginia Mamcasz-Viginheski ${ }^{1}$. Elsa Midori Shimazaki ${ }^{2}$
Sani de Carvalho Rutz da Silva ${ }^{3}$. Edilson Roberto Pacheco ${ }^{4}$

\begin{abstract}
Resumo: Esta pesquisa tem como objetivo buscar uma alternativa para desenvolver conceitos matemáticos com uma estudante cega total, os quais tenham sentido e contribuam para a sua aprendizagem e o seu desenvolvimento. A pesquisa apresenta uma abordagem qualitativa, sendo utilizado o estudo de caso como estratégia. Ela foi realizada em uma instituição não governamental que oferece atendimento especializado na área da deficiência visual, no município de Guarapuava, interior do Estado do Paraná. Fundamentados na teoria histórico-cultural de Vygotsky, procedemos a uma intervenção pedagógica para que a estudante elaborasse conceitos de Geometria e Álgebra. Os resultados mostraram que a estudante consolidou conceitos em fase de maturação, produzindo novos conceitos a partir deles. Também foi possível perceber que, independentemente das limitações, estudantes com deficiência visual são capazes de elaborar conceitos necessários para a autonomia e a participação social.
\end{abstract}

Palavras-chave: Ensino de Matemática. Formação de conceitos. Deficiente visual. Cego.

\begin{abstract}
The present research has as its principal aim to search for an alternative to develop mathematical concepts with a completely blind student, which may be meaningful and that contribute for her learning and development. The research presents a qualitative approach, using the case study as its strategy. It was carried out in a non-governmental institution that offers specialized care in the visual disability area, in Guarapuava, in the interior of Parana State. Based on Vygotsky's cultural history theory, we conducted a pedagogical intervention so that the student could elaborate concepts of Geometry and Algebra. The results showed that the student consolidated mature concepts, producing new ones from them. It was possible to perceive that, in spite of their limitations, students with visual disabilities are able to elaborate concepts that are necessary for their autonomy and social participation.
\end{abstract}

Keywords: Mathematics teaching. Concepts formation. Visual impairment. Blindness.

\footnotetext{
${ }^{1}$ Faculdade Guairacá, Colegiado de Matemática, Guarapuava, PR, Brasil. E-mail: <virginia@faculdadeguairaca. com.br>.

${ }^{2}$ Universidade Estadual de Maringá (UEM), Departamento de Teoria e Prática de Educação, Maringá, PR, Brasil.

${ }^{3}$ Universidade Tecnológica Federal do Paraná, Ponta Grossa, PR, Brasil.

${ }^{4}+$ In memoriam.
} 


\section{Introdução}

A busca de pressupostos teóricos e metodológicos que possam fornecer aportes ao ensino de Matemática tem se tornado uma preocupação cada vez mais evidente nas práticas pedagógicas. É importante pesquisar uma forma diferenciada de trabalho que possibilite ao estudante aprender de acordo com o seu próprio ritmo e com seus talentos, os quais se formam de modo individual em função das intervenções. A busca de alternativa de trabalho nos remete também ao processo de ensino e aprendizagem da pessoa com deficiência.

Apesar das contradições que emergem nos meios sociais, podemos encontrar pessoas com deficiência no ensino regular, no mercado de trabalho e em outros segmentos da sociedade, os quais devem estar preparados para a inclusão desses indivíduos. A escola precisa criar condições para que seja assegurado aos estudantes com deficiência o desenvolvimento cognitivo, social e afetivo esperado, por meio de adaptações curriculares, formação dos professores, adaptações físicas, entre outras.

Movidos pela preocupação em torno da criação de condições favoráveis à inclusão das pessoas com deficiência é que desenvolvemos este estudo. Estudantes com deficiência frequentando séries do ensino regular podem apresentar desempenho acadêmico suficiente, contudo, as pesquisas de Azevedo (2016), Viginheski et al. (2016), Mendes e Cia (2015), entre outras, têm mostrado que precisam de adaptações didático-metodológicas que minimizem ou eliminem as dificuldades que possam vir a surgir.

Salientamos que estudantes sem deficiência também podem apresentar dificuldades na apropriação de conteúdos matemáticos, cujas causas estão associadas a fatores que interferem no desenvolvimento e na aprendizagem, como adequação de materiais, preparo dos professores, utilização de uma única metodologia para ensinar todos os estudantes, entre outros. A deficiência é, assim, apenas mais um fator somado aos anteriormente citados.

Também sabemos que grande parte dos estudantes não elabora o conceito, pois o recebe pronto, contribuindo para o aumento da descrença na Matemática, o fracasso e o desinteresse. Ao nos referirmos à Matemática como uma ciência pronta, acabada e exata, muitas vezes enfatizamos para que seja considerada por nossos estudantes como a mais difícil. Esses fatores podem causar uma compreensão lacônica dessa ciência, ou seja, em termos de abstração, as etapas do conhecimento são queimadas, não sendo observado que a Geometria pode se constituir em uma articulação entre a Aritmética e a Álgebra.

Ao encontrarmos estudantes com deficiência visual no ensino regular, surge o questionamento de como lhes ensinar a Matemática, de forma que também possam elaborar seus conceitos, aprendendo-os e consolidando-os. Sendo assim, a pesquisa tem como objetivo principal buscar uma alternativa para desenvolver conceitos matemáticos com uma estudante cega, os quais tenham sentido e que contribuam para o desenvolvimento do processo de ensino e aprendizagem. Para tanto, partimos da preocupação em não trabalhar com conceitos considerados acabados ou prontos, mas elaborá-los, procurando relacioná-los com e nas situações cotidianas. O conceito, segundo Vygotski (1997), é formado pela mediação de outras pessoas e se dá atrelado à história do indivíduo.

Ao desenvolvermos os conceitos com nossos estudantes, abrimos espaço para que possam se apropriar dos conhecimentos elaborados historicamente pela humanidade, aos quais todos têm direito, pois são instrumentos necessários à cidadania. 


\section{Pressupostos teóricos}

Na busca pela sua subsistência, o homem desenvolveu atividades como caminhar, correr, pular, caçar, pescar, entre outras; nesse quadro, a história da humanidade tem mostrado que a sociedade manifestou diversas posturas e concepções em relação às pessoas com deficiência. Todavia, a organização social foi mudando, bem como os meios de produção, e novas correntes de pensamento começaram a surgir.

As atitudes de rejeição, inferioridade, segregação e mesmo o paternalismo e o assistencialismo são exemplos dessa postura, refletidos até hoje em diferentes situações. Durante muito tempo, acreditava-se que a melhor forma para a educação das pessoas com deficiência era mantê-las separadas, com programas visando suprir suas necessidades, diferentes dos demais. Essa modalidade de atendimento prolongou-se até meados do século passado, em que se notam mudanças e preocupações com a questão da educação das pessoas com deficiência (ARANHA, 2001; LIMA, 2006; PICCOLO; MENDES, 2012; SANTOS, 2010).

Vygotsky foi o fundador do Instituto de Defectologia, localizado em Moscou, aproximadamente entre os anos 1925 e 1934, reunindo em torno de si jovens cientistas que trabalhavam nas áreas da psicologia e no estudo das anormalidades físicas e mentais. Nesse instituto, as pessoas com deficiência eram educadas considerando-se as potencialidades, desprezando, assim, qualquer forma de tabular deficiência.

Leontiev (1991) relata sobre a existência de muitas crianças com dificuldades em aprender e seguir um ritmo normal, em condições também ditas normais. O teórico observou que, após a utilização de métodos especiais de ensino, muitas delas conseguiram superar o próprio atraso, via métodos especiais de ensino. Tal fato nos leva a refletir sobre a necessidade de se desenvolver uma prática pedagógica que crie condições para permitir a aprendizagem e o desenvolvimento das pessoas com deficiência, não as deixando à margem do processo de ensino e aprendizagem.

Muitos documentos foram elaborados pela sociedade com a finalidade de prestar amparo legal à pessoa com deficiência, entre eles a Declaração universal dos direitos humanos de 1949 (COORDENADORIA ECUMÊNICA DE SERVIÇO, 1978), que reconhece serem os direitos comuns a todos os homens, sem qualquer discriminação, destacando-se o direito à educação, e a Constituição da República Federativa do Brasil, promulgada em 1988 (BRASIL, 1989), que garante o direito de acesso ao Ensino Fundamental, obrigatório e gratuito a todos, assim como o atendimento educacional especializado às pessoas com deficiência, preferencialmente na rede regular de ensino.

A Lei de diretrizes e bases da educação nacional (LDBEN) (BRASIL, 1996) apresenta um capítulo destinado à Educação Especial, em que é definida como uma modalidade de educação escolar, oferecida preferencialmente na rede regular de ensino para os estudantes com deficiência, sendo lhes assegurado currículos, métodos, técnicas, recursos educativos conforme as necessidades, terminalidade específica, professores capacitados e formação para o trabalho.

É possível observar um grande avanço nesta área, com essa Lei, em comparação com a lei de diretrizes e bases (LDB) de 1961, que apresentava apenas um artigo se referindo à educação das pessoas com deficiência que, se possível, deveriam ser enquadradas no sistema geral da educação, com o objetivo de serem integrados à comunidade, e com a LDB de 1971, que garantia às pessoas com deficiência em atraso escolar tratamento especial de acordo com normas fixadas pelos Conselhos de Educação. 
A Declaração de Salamanca (DECLARAÇÃO..., 1994) teve como objetivo a aprovação de princípios, política e prática das necessidades educativas especiais e também o estabelecimento de uma linha de ação unificada.

Para os documentos Saberes e práticas da inclusão (BRASIL, 2006) e Política nacional de educação especial na perspectiva da educação inclusiva (BRASIL, 2008) a Educação Especial é uma modalidade de educação escolar que oferece para os estudantes com deficiência que frequentam os diferentes níveis de ensino o atendimento especial complementar ao atendimento do ensino regular, estabelecendo a interlocução com ele. Da maneira como a Educação Especial encontra-se definida, podemos dizer que se constitui em um conjunto de ações educacionais específicas às pessoas com deficiência, manifestadas de forma alternativa, procurando atender suas individualidades.

A Educação Inclusiva busca permitir o acesso das pessoas com deficiência junto aos outros, dentro das classes regulares. Vygotsky (1978) atribui à integração um fator importante para o desenvolvimento do ser humano. Para tanto, faz-se necessário adaptação curricular, sem perder de vista o conteúdo, a preparação do professor, a mobilização de toda a comunidade escolar, respeitando as diferenças e atendendo às necessidades individuais de todos.

Pessoas com deficiência podem ser definidas como aquelas que, por apresentarem algumas características específicas, necessitam de atendimento especializado. Dentre elas, citamos as pessoas com deficiência visual, foco desta pesquisa. De acordo a Convenção sobre os direitos das pessoas com deficiência (ONU, 2007, p. 2), a deficiência é "um conceito em evolução, resultado da interação entre a deficiência de uma pessoa e os obstáculos que impedem sua participação na sociedade. [...] Mede-se a deficiência pelo grau da impossibilidade de interagir com o meio da forma mais autônoma possível."

Segundo a Organização Mundial da Saúde (OMS), a partir da revisão realizada em 2006, a condição visual passou a ser classificada em quatro níveis: (i) visão normal; (ii) deficiência visual moderada; (iii) deficiência visual severa; e (iv) cegueira. À vista disso, o Conselho Brasileiro de Oftalmologia (CBO) classifica os níveis de deficiência visual moderada e severa como baixa visão (TALEB et al., 2012). Em conjunto com a cegueira, caracterizada pela perda total da visão ou resíduo mínimo, esses níveis determinam o público-alvo da Educação Especial na área da deficiência visual.

As pessoas com essa deficiência necessitam de métodos específicos e recursos didáticos adaptados na efetivação do processo de ensino e aprendizagem. As pessoas com baixa visão fazem uso de ampliações ou de equipamentos específicos para a leitura nos impressos à tinta.

A criação do código Braille para leitura e escrita por estudantes cegos facilitou o acesso deles à escola, possibilitando que as leituras e as interpretações fossem feitas por eles próprios, de maneira independente. Dada a evolução no campo da informática, livros, artigos, revistas, jornais e muitos materiais didáticos são impressos em Braille, facilitando ainda mais o acesso à produção escrita. Além do sistema Braille, as pessoas cegas podem contar também com recursos tecnológicos, que lhes permitem o acesso à informação e a comunicação em tempo real, como os leitores de tela, entre eles o Dos Vox, o Jaws, o NVDA, e outros.

Apesar das dificuldades ainda impostas pela sociedade, atualmente encontramos nas escolas regulares estudantes com deficiência visual, quer sejam cegos ou com baixa visão, que frequentam todos os níveis de ensino, desde a educação básica até o ensino superior. Para Vygotskii (1995), a cegueira não se trata apenas de uma deficiência, mas, em certo ponto, uma 
fonte de manifestação de suas capacidades; portanto, é preciso que se acredite que todas as pessoas podem aprender.

Percebemos, no entanto, a necessidade de uma metodologia diferenciada que possibilite a esses estudantes a aprendizagem dos conteúdos ensinados na escola e o seu desenvolvimento.

Vigotskii (2012) definiu como zona de desenvolvimento proximal a distância entre aquilo que a pessoa pode fazer de forma autônoma e o que precisa de ajuda para fazê-lo. Quando isso é constatado, a interferência de outras pessoas torna-se fundamental, pois favorece a relação do aprendizado com o ambiente sociocultural e sua interação com os demais. Dessa maneira, a educação das pessoas com deficiência visual junto aos outros indivíduos torna-se favorável também ao seu desenvolvimento; a falta de visão não o impede de frequentar o ambiente escolar, pois ele tem todas as condições para a aprendizagem, inclusive da Matemática.

Os talentos e as habilidades das pessoas deficientes, segundo Luria (1987), quando considerados, ancoram o desenvolvimento e a elaboração de atividades intelectual que leva à elaboração conceitual. Os conceitos são elaborados no processo de desenvolvimento social, nas relações com as outras pessoas e na cooperação com os parceiros sociais. É o trabalho conjunto que possibilita a formação das funções superiores. Assim, podemos afirmar que o conceito é elaborado por meio da mediação instrumental e depende daqueles que a pessoa vem formando ao longo da vida.

O conceito é parte integrante do processo intelectual usado na comunicação e para o entendimento e a resolução de problemas. Dessa forma, ele é mais que a soma de conexões associativas pela memória. É, sim, uma atividade mental superior, que se dá atrelada à história do próprio indivíduo (VIGOTSKII, 2012).

Ao discutir a formação de conceitos, Vigotskii (2012) mostra a história da formação das palavras, a partir do estudo da transformação dos significados. As palavras têm uma história e é a história dos homens. Como exemplo, podemos citar a palavra "matemática". O significado dela se modificou, absorvendo interesses e ideologias dos diversos grupos sociais. Como a maioria das palavras, matemática tem uma gênese, um processo histórico.

Dentro da visão histórico-cultural o professor atua como aquele que ajuda nas transformações dos significados das palavras. Para tanto, precisa avaliar os conceitos que os alunos já têm, que foram elaborandos nas mais diferentes interações. A partir da avaliação, atuar como guia, a fim de criar situações de aprendizagem para tornar em conhecimento científico, Vigotskii (2012) chama de conceitos espontâneos e científicos.

Vygotski (1997) separou os conceitos como espontâneos e científicos. Os primeiros se referem àqueles que aprendemos desde pequenos, em contato com objetos, fatos, fenômenos, entre outros; como científicos, considerou aqueles sistematizados e transmitidos intencionalmente, segundo uma metodologia específica, existindo sempre a partir de um sistema hierarquizado, do qual o conceito científico faz parte. Podemos exemplificar como conceitos científicos os que aprendemos em situação escolar, os quais são considerados aceitos pela comunidade científica. Uma das funções da escola é verificar os conceitos que os alunos já possuem, que aprenderam nas mais diversas interações e transformá-los em científicos por meio do processo ensino-aprendizagem.

Devido à sua preocupação com a questão do processo de ensino e de aprendizagem, em que a pessoa pode desenvolver atividades independentemente ou com ajuda de outras pessoas, Vygotsky (1978) desenvolveu o conceito de zona de desenvolvimento proximal considerando o 
nível de desenvolvimento e a capacidade potencial das pessoas para aprender determinadas coisas, definindo as funções que não foram amadurecidas, mas que estão em processo de maturação. Dessa forma, todos nós apresentamos diferentes habilidades que podem ser desenvolvidas e ampliadas por meio do processo de mediação.

Para Vygotsky (1978), o professor é aquele que utiliza instrumentos mediadores e planeja tarefas para que o aluno se aproprie do conhecimento, no caso, os conceitos matemáticos. Quando o professor utiliza de instrumentos mediadores, como a linguagem e outros desenvolvidos culturalmente na sociedade, o processo de elaboração de conceitos avança e se constitui a aprendizagem em direção ao desenvolvimento, tanto das pessoas cegas como das videntes, que têm direito de ter acesso aos conhecimentos formalmente elaborados pelos homens, que consideramos ser um dos instrumentos à cidadania. Podemos dizer que o conceito está formado quando se consegue abstrair e generalizar. A abstração e a generalização de conceitos dependem da história de cada um, mas ela é mediada pela atividade social, pelo signo e se dá em determinado contexto histórico cultural.

Em um momento histórico em que se pensa em educação inclusiva, aquela que procura respeitar as individualidades, oferecendo oportunidades a todos, necessita-se repensar quais são os objetivos que queremos atingir na educação de nossos alunos, sendo, igualmente, necessárias adaptações curriculares que contribuam para a formação de cidadãos atuantes.

\section{Metodologia}

Esta pesquisa apresenta uma abordagem qualitativa, sendo utilizado como estratégia o estudo de caso. Foi desenvolvida com uma estudante de 16 anos de idade, cega por glaucoma, em uma instituição especializada para atendimento a pessoas com deficiência visual e na residência da estudante.

A estudante ingressou no ensino regular quando tinha 7 (sete) anos, sendo alfabetizada junto aos demais alunos. Concomitante ao ensino regular, ela sempre recebeu apoio pedagógico em instituição especializada. No momento da pesquisa, ela frequentava a segunda série do curso de formação docente em nível médio, em um colégio público do município de Guarapuava, centro-oeste do Estado do Paraná.

A pesquisa foi realizada em 15 sessões, cujas atividades desenvolvidas se encontram sintetizadas no Quadro 1.

\section{Resultados e análises}

A Geometria, um dos ramos da Matemática, apresentou-se, em princípio, como consequência empírica, a partir de pequenas observações e experiências, crescendo gradativamente e se transformando posteriormente em conhecimento sistematizado. Foi considerada por Davis e Hersch (1989) como uma ciência que relaciona a Matemática com o espaço e vem contribuindo para que possamos desenvolver o pensamento lógico. 
Quadro 1. Blocos de atividades

\begin{tabular}{|c|c|c|c|}
\hline Etapa & Atividade & Objetivo & Recursos \\
\hline 1 & $\begin{array}{l}\text { Geometria plana: } \\
\text { classificação de figuras } \\
\text { geométricas }\end{array}$ & $\begin{array}{l}\text { Classificar figuras conforme } \\
\text { atributos. }\end{array}$ & Figuras geométricas \\
\hline 2 & $\begin{array}{l}\text { Construção de maquete de } \\
\text { um cômodo da residência } \\
\text { da aluna }\end{array}$ & Elaborar conceito de área. & $\begin{array}{l}\text { Embalagens; } \\
\text { Material dourado }\end{array}$ \\
\hline 3 & Cálculo de áreas & $\begin{array}{l}\text { Determinar a quantidade de } \\
\text { unidades quadradas de peças } \\
\text { retangulares e quadrangulares } \\
\text { graduadas; } \\
\text { Propiciar a associação entre } \\
\text { Geometria e Álgebra. }\end{array}$ & $\begin{array}{l}\text { Placas retangulares e } \\
\text { quadrangulares graduadas; } \\
\text { Figuras geométricas em } \\
\text { relevo. }\end{array}$ \\
\hline 4 & $\begin{array}{l}\text { Medidas do cômodo e dos } \\
\text { móveis }\end{array}$ & $\begin{array}{l}\text { Efetuar medidas para o cálculo } \\
\text { de áreas. }\end{array}$ & $\begin{array}{l}\text { Instrumentos de medidas } \\
\text { não convencionais e } \\
\text { convencionais (metro) }\end{array}$ \\
\hline 5 & Cálculo algébrico de áreas & $\begin{array}{l}\text { Calcular áreas de superfícies } \\
\text { sem graduação }\end{array}$ & $\begin{array}{l}\text { Placas retangulares e } \\
\text { quadrangulares não } \\
\text { graduadas }\end{array}$ \\
\hline
\end{tabular}

Fonte: elaborado pelos autores.

Os gregos desenvolveram a Geometria de forma demonstrativa. Assim, a Álgebra desenvolvida por eles se tornou de fácil compreensão por ser geométrica e, em decorrência disso, ser demonstrativa também, diferenciando-se da Álgebra desenvolvida por outros povos. Assim, podemos considerar a Geometria um caminho para o desenvolvimento da Álgebra que, em seu sentido mais amplo, trata das operações sob formas simbólicas. Ao iniciar o trabalho com a aluna cega utilizando a Geometria como uma ponte para aprender a Álgebra, houve a necessidade de retomar alguns conceitos já vistos pela aluna no Ensino Fundamental.

Para Vygotsky (1978), o papel do professor é planejar tarefas para que possa, de forma intencional, estabelecer a aprendizagem. Para isso, é necessário identificar e interferir constantemente na zona de desenvolvimento proximal do aluno, contribuindo para que o processo de ensino e aprendizagem aconteça; ao verificarmos se o conceito sobre área estava ou não consolidado pela estudante, pôde-se constatar que, pela resposta obtida “área é igual a a vezes b?", o conceito que já havia sido trabalhado em outras situações formais, provavelmente de forma mecânica e repetitiva, não estava consolidado, uma vez que a expressão trata da área específica de alguns quadriláteros e não de área, de uma maneira generalizada.

Uma das primeiras etapas da pesquisa, buscando a consolidação do conceito de área, foi a construção de uma maquete que representaria algum ambiente escolhido pela estudante, no caso, seu quarto. Solicitamos que o descrevesse quanto à forma, à maneira como os móveis estavam dispostos no quarto e a posição dele em relação à casa. Identificou seu quarto como tendo a forma retangular e, quando a questionada por que era retangular, ela respondeu: "tem os lados diferentes". Quanto ao quadrado, classificou-o como figura geométrica que tem "lados iguais". 
Buscando uma forma que levasse a estudante a visualizar outras características específicas que definisse cada figura geométrica, não restringindo apenas aos lados, foram desenvolvidas atividades de classificação com diferentes figuras geométricas em relevo. A classificação, segundo Luria (2012), caracteriza-se pelo isolamento de atributos diferentes dos objetos, e o pensamento classificatório, compartilhado por meio da linguagem, torna-se um instrumento para a abstração e a generalização. Na primeira atividade, ela classificou as figuras pela forma. Em uma segunda classificação, separou pelo atributo número de lados, construindo grupos de triângulos, quadriláteros, pentágonos, entre outros.

A terceira classificação se deu somente entre os quadriláteros. A estudante verificou que a diferença entre as figuras geométricas não era atribuída apenas pelos lados, mas também pelos ângulos. Por meio da atividade, observamos que experiências realizadas pela própria estudante, expressas pela linguagem, facilitaram a compreensão das diferenças entre as figuras; tais experiências são fatores importantes para que a aprendizagem aconteça (LURIA, 2012; VYGOTSKI, 1997).

$\mathrm{Na}$ etapa seguinte, trabalhou-se o conceito de área e se explorou a noção de espaço utilizando a maquete do quarto da estudante. A maquete foi construída utilizando embalagens, escolhidas por ela, fazendo uso da proporcionalidade. Partindo do tridimensional para o bidimensional e buscando relacionar o quadrado, retângulo, ou qualquer outra figura geométrica com um sólido, as caixas foram planificadas, utilizando materiais de diversas texturas e barbante para delimitar o espaço.

Partindo da expressão para área apresentada pela estudante como $a \times b$, e por meio do uso do material dourado, desenvolvido pela educadora italiana Maria Montessori (1870-1952), escolhido por apresentar medidas graduadas, constituindo-se em uma alternativa ao trabalho com medidas para o aluno cego, foram trabalhadas as unidades de medida em blocos bidimensionais.

As primeiras atividades desenvolvidas com o material dourado nos mostraram a necessidade da confecção de materiais específicos para a consolidação do conceito de área como medida de superfície. O material confeccionado era constituído por placas de madeira, com formas retangulares e quadrangulares, que, juntas, se completavam formando um quadrado. Uma das faces era graduada, como o material dourado e a outra face, não graduada, apenas com diferentes texturas. Esse material foi desenvolvido e utilizado com a estudante tendo por objetivo determinar a quantidade de unidades quadradas em cada uma. A Figura 1 representa o material confeccionado.

A estudante foi calculando a área contando as unidades quadradas de cada peça. Ao juntarmos as figuras geométricas 4, 5, 7 e 8, calculou a área desta maneira:

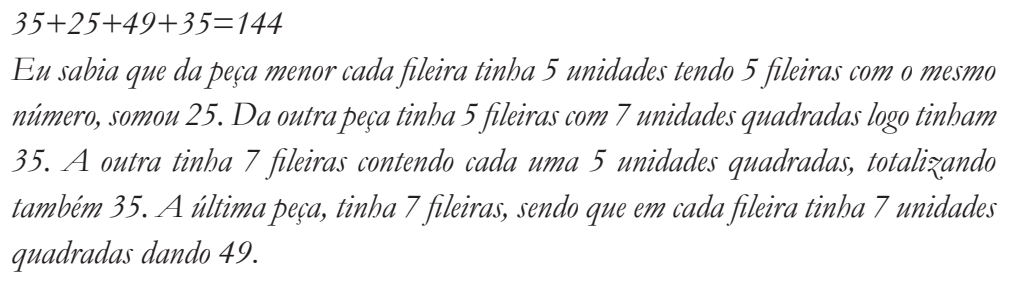


Figura 1. Adaptação de material em relevo

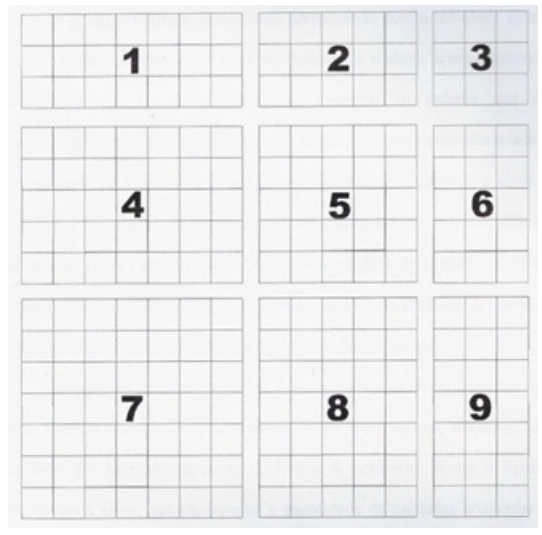

Fonte: Acervo dos pesquisadores.

Podemos observar que, dada a maneira como a estudante desenvolveu os cálculos, confirmou-se a apropriação do conceito de multiplicação como soma de parcelas. Nota-se que através do vocábulo também, utilizado pela estudante para se referir ao resultado do produto de 5 por 7 e 7 por 5 , estabelece a propriedade comutativa da multiplicação.

Ao ser questionada sobre como calcular a área das peças 4, 5, 7 e 8, justapostas, respondeu: "conta este lado [lado esquerdo] com o outro [lado inferior] e soma os dois". Perguntamos então como havia feito com uma peça apenas, ao que respondeu: "Achei quanto valiam dois lados e multipliquei, então a grande é a mesma coisa. Conto os dois lados e multiplico".

Nas atividades seguintes, ela observou que, tendo a mesma quantidade de unidades nos dois lados, a figura formada era um quadrado. Complementamos sua observação, comentando por que utilizamos o termo ao quadrado, pois realmente as quantidades iguais nos dois lados formam um quadrado.

Os cálculos anteriores serviram de suporte para se determinar a medida do espaço livre do cômodo da casa da estudante. Para efetuar as medições, utilizamos várias unidades de medida convencionais e não convencionais. Comparando os resultados encontrados, fazendo uso de diferentes instrumentos, a aluna concluiu ser necessária a utilização de um instrumento padrão. Nesse momento, comentamos também sobre a necessidade que o homem teve de padronizar um único sistema de medidas (TOLEDO; TOLEDO, 2009).

A estudante comentou que professores de Matemática já haviam proposto na escola atividades envolvendo grandezas e medidas e que seus colegas desenvolviam as atividades por ela, ditando-lhe os valores encontrados. Ela apenas realizava os cálculos. Eram comuns situações semelhantes em outras atividades. Para ela, essa atitude fazia parecer que não acreditavam que ela também poderia desenvolver algumas atividades como os outros.

Pelo fato de a estudante haver concluído que, para descobrir as unidades quadradas de alguma superfície era necessário multiplicar um lado pelo outro, mediu apenas duas dimensões de cada móvel. Depois de efetuadas as medidas, foram calculadas as áreas de todos os móveis do quarto e calculada a área que ela tinha livre para transitar. 
A partir da fase numérica, foram utilizadas as placas com faces não graduadas com o propósito de buscar uma representação para a área das placas. Foram utilizadas as peças 4, 5, 7 e 8, com a face não graduada voltada para cima. Ao ser indagada sobre como calcular a área das figuras geométricas cujas dimensões não eram conhecidas, respondeu: "medir, como foi feito no quarto". A sua resposta se configurou, nesse momento, como uma generalização.

Ao perceber a diferença entre a face graduada e não graduada, respondeu que teria que multiplicar um lado pelo outro para encontrar a área. Sobrepondo alguns objetos de tamanhos diferentes sobre a peça, a aluna observou essas diferenças através do tato, concluindo: " $a$ medida do lado depende da unidade que usamos para medir". Por meio de suas respostas, demonstrou novamente uma generalização como solução para a situação apresentada.

A estudante atribuiu aos lados das peças as variáveis x e y, concluindo que o quadrado 7 teria área $\mathrm{x}^{2}$, os retângulos 4 e 8 teriam área de x.y e a área do quadrado 5 seria $\mathrm{y}^{2}$, despertando para a inserção do elo Geometria-Álgebra. Nessas situações, observamos que, com o suporte do material elaborado, o trânsito entre as fases numérica e algébrica ficou facilitado, pois, com os referenciais dos cálculos efetuados, a aluna foi capaz de observar que a maneira como procedeu em uma situação pôde servir como veio para outra.

Partimos então para a determinação da expressão da área de diferentes espaços quadrangulares e retangulares não graduados. A expressão das somas das áreas decorreu do desenvolvimento, conforme a Figura 2.

Figura 2. Expressão aritmética e algébrica da soma de áreas

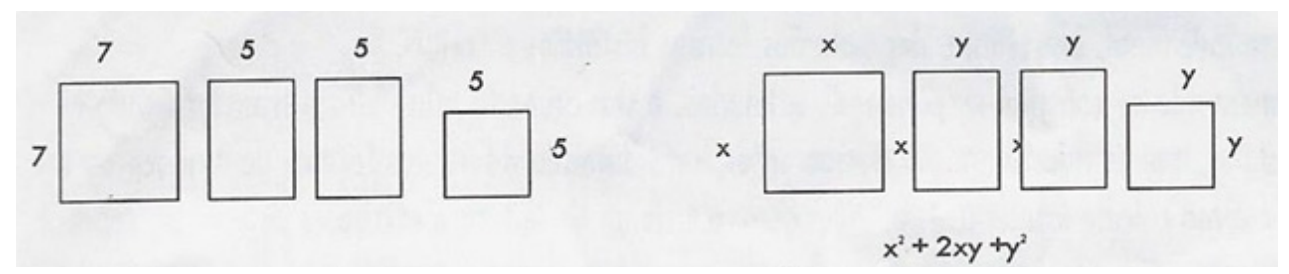

Fonte: Acervo dos pesquisadores.

Ao propormos várias atividades de produtos de soma, representados por quadrados da soma, a estudante observou serem comuns em todas as atividades: "a multiplicação do primeiro e o segundo. É sempre duas vezes, dois quadrados, um do primeiro e outro do segundo".

Ao questionarmos suas afirmações de que, em todas as situações, encontrou resultados representados da mesma forma, voltou, conferiu os cálculos e ratificou sua resposta. Ressaltou que a única diferença eram as letras e os números, demonstrando com isso uma generalização.

Identificamos nessa atividade a abstração, no sentido em que as propriedades das situações numéricas foram internalizadas, ou seja, abstraídas e generalizadas nas situações algébricas. Para Vygotski (1997), a abstração, somada ao pensamento mais avançado, permite a formação do conceito. Podemos afirmar, dessa forma, a consolidação do conceito sobre o produto entre a soma de dois termos, ou seja, o quadrado da soma. 
Acreditamos que as atividades desenvolvidas durante toda a pesquisa buscando a formação de conceitos matemáticos foram válidas, pois observamos que, por meio delas, a estudante consolidou muitos conceitos que estavam em fase de maturação e também novos conceitos foram elaborados a partir dos já consolidados, possibilitando, assim, a abstração, inerentes à formulação do pensamento algébrico e geométrico, segundo a proposta deixada por Vigotskii (2012), para a situação de ensino e aprendizagem; tal proposta considera que o bom ensino se adianta ao desenvolvimento, pois, pela criação de zonas de desenvolvimento proximal, o professor auxilia para o aparecimento de novas funções ainda não desenvolvidas.

Constatamos outros resultados, tais como a multiplicação como soma de parcelas, a noção de área como medida e observar a articulação com a propriedade comutativa da adição e da multiplicação.

Após o nosso trabalho pedagógico, elucidaram-se outras maneiras do cálculo de área. Dos conceitos formados pela estudante, o mais relevante foi de que a área é "a quantidade de unidades quadradas que formam uma superficie".

Verificamos também que, em todo o momento em que a Geometria, utilizada como elo entre as fases aritmética e algébrica esteve presente, ela foi de fundamental importância para a estudante elaborar os conceitos.

Muitos professores de Matemática não estabelecem esse vínculo, não percebendo ainda a importância desse procedimento. Abordam diretamente os conceitos algébricos e isso pode se constituir como uma das causas para a aversão à Matemática. D’Ambrósio (1996) alerta que ensinar a Matemática sem sentido, desvinculada da realidade do estudante, ocasiona também um desinteresse; em consequência disso, o rendimento escolar torna-se cada vez mais baixo.

\section{Considerações finais}

Verificamos, por meio desta pesquisa que, para se buscar formas para minimizar o fracasso no ensino da Matemática, é relevante que os professores e os pesquisadores busquem maneiras prazerosas para tal ensino. É fundamental considerar os conceitos que os estudantes já têm e tomá-los como ponto de partida para, juntos, elaborarem novos conceitos, aqueles cientificamente aceitos.

Faz-se necessário entender e mostrar aos estudantes o conteúdo e a forma da Matemática, e lhes demonstrar que ela está no cotidiano das nossas vidas, não havendo razão para temê-la, mas utilizá-la como forma de sobrevivência e transcendência.

Essa experiência de ensino e aprendizagem de conceitos matemáticos ratificou que as pessoas com deficiência, mesmo inseridas no ensino regular, precisam de apoio pedagógico específico. Aqui pontuamos a importância da Educação Especial. Não a tomamos como uma forma de manter estudantes segregados, mas atribuímos a ela a fundamental importância em oferecer suporte pedagógico aos professores e estudantes.

Podemos afirmar que, independentemente das limitações, no caso a deficiência visual, as pessoas formam conceitos necessários à sua cidadania e à autonomia.

Foi a partir de nossas preocupações com a questão da Educação, especificamente a Especial, e pelas experiências vividas que esta pesquisa foi desenvolvida. Salientamos também que, trabalhando de maneira semelhante em nossas turmas, no ensino regular, estaremos contribuindo para um ensino que acresça para o desenvolvimento de nossos estudantes. 
A pesquisa é uma contribuição para a Educação Especial e para o Ensino de Matemática. É importante que outras experiências se façam para que se verifique como a elaboração dos conceitos matemáticos se processa em estudantes com deficiência.

\section{Referências}

ARANHA, M. S. F. Paradigmas da relação da sociedade com as pessoas com deficiência. Revista do Ministério Público do Trabalho, Brasília, v. 11, n. 21, p. 160-173, 2001.

Disponível em: <http://www.adiron.com.br/arquivos/paradigmas.pdf >. Acesso em: 2 out. 2017.

AZEVEDO, F. C. Alfabetização e letramento em alunos com deficiência intelectual no ensino regular. 2016. 138 f. Dissertação (Mestrado em Educação) - Universidade Estadual de Maringá, Maringá, 2016.

BRASIL. Lei $\mathbf{n}^{\circ}$ 9.394, de 20 de dezembro de 1996. Estabelece as diretrizes e bases da educação nacional. Brasília, 1996. Disponível em: <http://www.planalto.gov.br/ccivil_03/ leis/L9394.htm>. Acesso em: 2 out. 2017.

BRASIL. Ministério da Educação. Constituição da República Federativa do Brasil 1988. Brasília, 1989.

Brasilia, 2008.

Política nacional de educação especial na perspectiva da educação inclusiva.

Saberes e práticas da inclusão: desenvolvendo competências para o atendimento às necessidades educacionais especiais de alunos cegos e de alunos com baixa visão. Brasília, 2006.

COORDENADORIA ECUMÊNICA DE SERVIÇO. Declaração universal dos direitos humanos. Salvador: Paulinas, 1978.

DAVIS, P. J.; HERSH, R. A experiência matemática.4. ed. Rio de Janeiro: F. Alves, 1989.

D’AMBRÓSIO, U. Educação matemática: da teoria à prática. Campinas: Papirus, 1996.

DECLARAÇÃO de Salamanca e linha de ação sobre necessidades educativas especiais.

Salamanca, 1994. Disponível em: < http://portal.mec.gov.br/seesp/arquivos/pdf/salamanca. pdf>. Acesso em: 2 out. 2017.

LIMA, P. A. Educação inclusiva e igualdade social. São Paulo: Avercamp, 2006.

LEONTIEV, A. N. Os princípios do desenvolvimento mental e o problema do atraso mental. In: LURIA, A. et al. Psicologia e pedagogia: bases psicológicas da aprendizagem e do desenvolvimento. São Paulo: Moraes, 1991. p. 59-94.

LURIA, A. R. Diferenças culturais de pensamento. In: VIGOTSKII, L. S.; LURIA, A. R.; LEONTIEV, A. N. Linguagem, desenvolvimento e aprendizagem. 12. ed. São Paulo: Ícone, 2012. p. 39-58. 
LURIA, A. R. Pensamento e linguagem: as últimas conferências de Luria. Porto Alegre: Artes Médicas, 1987.

MENDES, E. G.; CIA, F . National observatory on special education: network study about inclusive education in Brazil. Open Journal of Social Sciences, Irvine, v. 3, n. 9, p. 60-64, 2015. Disponível em: <https://doi.org/10.4236/jss.2015.39009>. Acesso em: 2 out. 2017.

ORGANIZAÇÃO DAS NAÇÕES UNIDAS. Convenção sobre os direitos das pessoas com deficiência. Nova Iorque, 2007. Disponível em: <http://www.mpgo.mp.br/ portalweb/hp/41/docs/comentarios_a_convencao_sobre_os_direitos_das_pessoas_com_ deficiencia.pdf>. Acesso em: 2 out. 2017.

PICCOLO, G. M.; MENDES, E. G. Nas pegadas da história: tracejando relações entre deficiência e sociedade. Revista Educação Especial, Santa Maria, v. 25, n. 42, p. 29-42, 2012. Disponível em: <http://www.redalyc.org/articulo.oa?id=313127404003 >. Acesso em: 2 out. 2017.

SANTOS, I. M. Inclusão escolar e a educação para todos. 2010. Tese (Doutorado em Educação) - Universidade Federal do Rio Grande do Sul, Porto Alegre, 2010.

TALEB, A. et al. As condições de saúde ocular no Brasil. São Paulo: Conselho Brasileiro de Oftalmologia, 2012.

TOLEDO, M. B. A.; TOLEDO, M. A. Teoria e prática de matemática: como dois e dois. São Paulo: FTD, 2009.

VIGINHESKI, L. V. M. et al. An approach for the teaching of notable products in an inclusive class: the case of a student with visual Disabilities. European Journal of Special Education Research, Bucharest, v. 1, n. 2, p. 24-40, 2016. Disponível em: <https:// oapub. org/edu/index.php/ejse/article/view/103/246>. Acesso em: 2 out. 2017.

VIGOTSKII, L. S. Aprendizagem e desenvolvimento intelectual na idade escolar. In: VIGOTSKII, L. S.; LURIA, A. R.; LEONTIEV, A. N. Linguagem, desenvolvimento e aprendizagem. 12. ed. São Paulo: Ícone, 2012. p. 103-118.

VYGOTSKI, L. S. Pensamiento y linguaje: obras escogidas 2. Madri: Visor, 1997.

VYGOTSKII, L. S. Fundamentos de defectología. Havana: Pueblo y Education, 1995. (Obras completas, tomo 5).

VYGOSTSKY, L. S. Mind in society: the development of higher psychological processes. Cambriage: Harvard University Press: 1978.

\footnotetext{
Artigo recebido em 08/09/2016. Aceito em 14/03/2017.

Endereço para contato: Faculdade Guairacá, Colegiado de Matemática, Rua XV de Novembro, 7050, Centro, CEP 85010-000, Guarapuava, PR, Brasil.
} 
